\title{
Impact of Multiple Prostate Biopsies: Risk of Perioperative Complications and Biochemical Recurrence After Radical Prostatectomy
}

\author{
Kyong Min Park', Jae-Wook Chung ${ }^{1}$, Jun-Koo Kang ${ }^{1}$, Teak Jun Shin ${ }^{2}$, \\ Se Yun Kwon ${ }^{3}$, Hyun Chan Jang ${ }^{4}$, Yun-Sok $\mathrm{Ha}^{1}$, Seock Hwan Choi ${ }^{1}$, \\ Wonho Jung ${ }^{2}$, Jun Nyung Lee ${ }^{1}$, Byung Hoon Kim², Bum Soo Kim ${ }^{1}$, \\ Hyun Tae Kim ${ }^{1}$, Jae Soo Kim ${ }^{4}$, Tae-Hwan $\mathrm{Kim}^{1}$, Eun Sang Yoo', \\ Kyung Seop Lee ${ }^{3}$, Chun II Kim², Sung Kwang Chung ${ }^{1}$, Tae Gyun Kwon ${ }^{1,5}$ \\ ${ }^{1}$ Department of Urology, School of Medicine, Kyungpook National University, Daegu, Korea \\ ${ }^{2}$ Department of Urology, Keimyung University School of Medicine, Daegu, Korea \\ ${ }^{3}$ Department of Urology, Dongguk University College of Medicine, Gyeongju, Korea \\ ${ }^{4}$ Department of Urology, Daegu Fatima Hospital, Daegu, Korea \\ ${ }^{5}$ Joint Institute for Regenerative Medicine, Kyungpook National University, Daegu, Korea
}

Purpose: The aim of this study was to analyze the perioperative complications and oncological outcomes of radical prostatectomy (RP) in patients who underwent multiple prostate biopsies.

Materials and Methods: A total of 1,112 patients who underwent RP between January 2009 and April 2016 at 4 different centers were included in this study. We divided these patients into 2 groups: patients who underwent only 1st biopsy, and those who underwent 2 nd or more repeated biopsies. The association between the number of prior biopsies and perioperative complications and biochemical recurrence (BCR) was analyzed.

Results: Of 1,112 patients, 1,046 patients $(94.1 \%)$ underwent only 1st biopsy, and $66(5.9 \%)$ underwent 2nd or more repeated biopsies. There were no significant differences in preoperative prostate-specific antigen levels, operation times, blood loss volumes, or hospital stay durations (all $p>0.05$ ). Patients who underwent multiple prostate biopsies presented with a localized tumor significantly more often $(p<0.05)$. The Gleason score and rate of positive surgical margins were significantly lower in patients with multiple biopsies (all $p<0.05)$. The Cox proportional hazards model analysis indicated that there was no association between the number of prior prostate biopsies and BCR $(p>0.05)$. Kaplan-Meier curve analysis indicated that BCR-free survival rates between the 2 groups were similar $(p>0.05)$.

Conclusions: Multiple prostate biopsies are not associated with an increased risk of perioperative complications, adverse pathological outcomes, or higher rates of BCR in patients who have undergone RP. (Korean J Urol Oncol 2020;18:24-31)

Key Words: Prostate cancer $\cdot$ Radical prostatectomy $\cdot$ Multiple prostate biopsy $\cdot$ Perioperative complication • Biochemical recurrence

Received November 7, 2019, Revised December 23, 2019,

Accepted January 14, 2020

Comesponding Author: Tae Gyun Kwon

Department of Urology, School of Medicine, Kyungpook

National University, 807 Hoguk-ro, Buk-gu, Daegu 41404, Korea

E-mail: tgkwon@knu.ac.kr

Tel: +82-53-200-2166, Fax: +82-53-321-3207

ORCID: https://orcid.org/0000-0002-4390-0952

\section{INTRODUCTION}

Prostate cancer $(\mathrm{PCa})$ is the most common solid malignancy, ranking third in cancer in 2017 with approximately 161,360 new diagnoses and 26,730 deaths in the United

This is an Open Access article distributed under the terms of the Creative Commons Attribution Non-Commercial License (http://creativecommons.org/licenses/by-nc/4.0/) which permits unrestricted non-commercial use, distribution, and reproduction in any medium, provided the original work is properly cited. 2020 (C) Copyright The Korean Urological Oncology Society and The Korean Prostate Society. All Rights Reserved. 
States. ${ }^{1}$ The incidence of PCa has increased gradually in several Asian countries, and PCa has consistently become one of the main cancers of Asian people. ${ }^{2}$ Likewise, in Korea, patients of $\mathrm{PCa}$ has steadily increased over the last 10 years. $^{3}$

Prostate-specific antigen (PSA) is the most valuable serum marker used for the early detection and management of PCa. ${ }^{4}$ It is a noted fact that elevation of serum PSA levels and/or abnormal digital rectal examination findings are indications for prostate biopsy. ${ }^{5}$ Prostate biopsy is the reliable standard method to diagnose PCa. ${ }^{6}$ However, in many cases, an initial prostate biopsy is negative. ${ }^{7}$ Approximately more than $20 \%$ of patients are diagnosed with $\mathrm{PCa}$ upon a first biopsy; however, the remaining patients are followed clinically via regular of sampling serum PSA or performing a second prostate biopsy. ${ }^{8}$ Because the volume of prostate obtained during a biopsy is considerably little, these patients may have $\mathrm{PCa}$, in spite of presenting negative results at the initial biopsy. ${ }^{9}$

There are no clear guidelines concerning to repeat prostate biopsy in men with negative results upon an initial biopsy. Indications for a second prostate biopsy includes consistently rising and/or stationary high PSA serum levels, abnormal digital rectal examination findings, ${ }^{6}$ atypical small acinar proliferation or prostatic intraepithelial neoplasia revealed upon initial prostate biopsy, ${ }^{5}$ or treatment strategies such as active surveillance of $\mathrm{PCa} .{ }^{10}$ However, there are no fixed guidelines on when or whether to repeat prostate biopsies in patients with negative findings in the initial biopsy. ${ }^{11}$

The preceding studies demonstrated when repeating a prostate biopsy, the diagnosed PCa is less seem to be of high grade. ${ }^{12,13}$ Furthermore, other studies have suggested that a patient who undergoes radical prostatectomy after repeat biopsy harbors PCa which is associated with better pathological outcomes. ${ }^{14,15}$ However, to date, there have been few studies concerning the relationship between the number of prostate biopsies and perioperative complications or biochemical recurrence (BCR) after radical prostatectomy.

Therefore, we analyzed whether repeated prostate biopsies before radical prostatectomy were related to different perioperative complications or oncologic and pathological outcomes. In particular, we presumed that 2 nd or more repeated prostate biopsies would be related to better oncologic and pathological outcomes, but perioperative outcomes were worse.

\section{MATERIALS AND METHODS}

\section{Patients Selection and Study Design}

From January 2009 to April 2016, 4 centers gathered the patients who were diagnosed as PCa and underwent radical prostatectomy. We excluded patients who did not undergo regular follow-up, who received neoadjuvant or adjuvant hormone/radiation therapy, and who presented with malignant solid tumors other than in the prostate. Finally, 1,112 patients met these criteria and we divided 2 groups. "1st biopsy" group and "2nd or more repeated biopsies" group. We retrospectively reviewed the medical records of the patients and analyzed whether there were any associations between the number of prior biopsies and BCR (defined as 2 consecutive measurements of PSA levels $\geq 0.2 \mathrm{ng} / \mathrm{mL}$ ) or perioperative complications.

\section{Statistical Analysis}

Patient characteristics were analyzed using the chi-square test (pathologic T stage, Gleason score, surgical technique, lymphovascular invasion, surgical margin status, BCR) and Fisher exact test (D'Amico classification, Clavien-Dindo complications). The Student t-test was used for age, body mass index (BMI) scores, preoperative PSA levels, estimated blood loss volumes, operation times, hospital stay durations, time to removal of urethral catheter, and follow-up periods. In addition, multivariable Cox regression was used for the analysis of the impact of the number of prostate biopsies on BCR, and Kaplan-Meier curves via a log-rank test were used for the analysis of BCR-free survival. In addition, propensity-matching scores were calculated for each per patient by chi-square test using the age, BMI, PSA, D'Amico classification. Statistical analysis was performed using SPSS ver. 16.0 (SPSS Inc., Chicago, IL, USA), and $\mathrm{p}<0.05$ was considered statistically significant.

This study was approved by the Ethics Committee of the Kyungpook National University School of Medicine (IRB number: KNUH 2017-06-011).

\section{RESULTS}

Among 1,112 patients, 1,046 patients (94.1\%) did 1st bi- 
opsy and only $66(5.9 \%)$ did 2nd or more repeated biopsies. Perioperative characteristics and pathologic outcomes according to the number of prior biopsies are shown in Table 1.
The mean age was $66.6 \pm 6.3$ years, and the mean BMI was $24.2 \pm 2.8 \mathrm{~kg} / \mathrm{m}^{2}$; there were no significant differences between the 2 groups ( $\mathrm{p}=0.144$ and $\mathrm{p}=0.897$, respectively).

Table 1. Perioperative characteristics and pathologic outcomes according to number of prior biopsies

\begin{tabular}{|c|c|c|c|c|}
\hline \multirow{2}{*}{ Variable } & \multirow{2}{*}{ Overall } & \multicolumn{2}{|c|}{ No. of biopsy sessions } & \multirow{2}{*}{ p-value } \\
\hline & & 1 & $\geq 2$ & \\
\hline No. of patients & $1,112(100)$ & $1,046(94.1)$ & $66(5.9)$ & - \\
\hline Age (yr) & $66.6 \pm 6.3$ & $66.5 \pm 6.3$ & $67.7 \pm 5.8$ & 0.144 \\
\hline Body mass index $\left(\mathrm{kg} / \mathrm{m}^{2}\right)$ & $24.2 \pm 2.8$ & $24.2 \pm 2.8$ & $24.2 \pm 2.9$ & 0.897 \\
\hline Preoperative PSA (ng/mL) & $11.8 \pm 10.5$ & $11.8 \pm 10.7$ & $12.0 \pm 7.5$ & 0.883 \\
\hline D'Amico classification & & & & $0.058^{*}$ \\
\hline Low & $81(7.3)$ & $71(6.8)$ & $10(15.2)$ & \\
\hline Intermediate & $619(55.7)$ & $585(55.9)$ & $34(51.5)$ & \\
\hline High & $412(37.1)$ & $390(37.3)$ & $22(33.3)$ & \\
\hline Pathologic $\mathrm{T}$ stage & & & & 0.003 \\
\hline $\mathrm{T} 2$ & $651(58.5)$ & $599(57.3)$ & $52(78.8)$ & \\
\hline $\mathrm{T} 3 \mathrm{a}$ & $313(28.1)$ & $304(29.1)$ & $9(13.6)$ & \\
\hline$\geq \mathrm{T} 3 \mathrm{~b}$ & $148(13.3)$ & $143(13.7)$ & $5(7.6)$ & \\
\hline Gleason score & & & & 0.002 \\
\hline 6 & $126(11.3)$ & $109(10.4)$ & $17(25.8)$ & \\
\hline 7 & $700(62.9)$ & $664(63.5)$ & $36(54.5)$ & \\
\hline 8 & $146(13.1)$ & $139(13.3)$ & $7(10.6)$ & \\
\hline$\geq 9$ & $140(12.6)$ & $134(12.8)$ & $6(9.1)$ & \\
\hline Surgical technique & & & & 0.451 \\
\hline Open & $223(20.1)$ & $211(20.2)$ & $12(18.2)$ & \\
\hline Laparoscopic & $146(13.1)$ & $134(12.8)$ & $12(18.2)$ & \\
\hline Robot-assisted & $743(66.8)$ & $701(67.0)$ & $42(63.6)$ & \\
\hline Lymphovascular invasion & & & & 0.614 \\
\hline No & $990(89.0)$ & $930(88.9)$ & $60(90.9)$ & \\
\hline Yes & $122(11.0)$ & $116(11.1)$ & $6(9.1)$ & \\
\hline Surgical margin status & & & & 0.001 \\
\hline Negative & $564(50.7)$ & $518(49.5)$ & $46(69.7)$ & \\
\hline Positive & $548(49.3)$ & $528(50.5)$ & $20(30.3)$ & \\
\hline Estimated blood loss (mL) & $265.8 \pm 149.1$ & $267.3 \pm 150.4$ & $242.6 \pm 125.1$ & 0.129 \\
\hline Operation time (min) & $226.4 \pm 60.4$ & $226.8 \pm 61.2$ & $221.6 \pm 47.1$ & 0.399 \\
\hline Hospital stay (day) & $9.1 \pm 2.8$ & $9.1 \pm 2.9$ & $8.7 \pm 2.6$ & 0.280 \\
\hline Time to removal of urethral catheter (day) & $7.5 \pm 2.0$ & $7.5 \pm 2.0$ & $7.6 \pm 1.0$ & 0.414 \\
\hline Clavien-Dindo complication & & & & $0.881^{*}$ \\
\hline None & $923(83.0)$ & $869(83.1)$ & $54(81.8)$ & \\
\hline I & $33(3.0)$ & $31(3.0)$ & $2(3.0)$ & \\
\hline II & $104(9.4)$ & $98(9.4)$ & $6(9.1)$ & \\
\hline IIIa & $38(3.4)$ & $35(3.3)$ & $3(4.5)$ & \\
\hline IIIb & $14(1.3)$ & $13(1.2)$ & $1(1.5)$ & \\
\hline$\geq \mathrm{IV}$ & $0(0)$ & $0(0)$ & $0(0)$ & \\
\hline Biochemical recurrence & & & & 0.414 \\
\hline No & $901(81.0)$ & $845(80.8)$ & $56(84.8)$ & \\
\hline Yes & $211(19.0)$ & $201(19.2)$ & $10(15.2)$ & \\
\hline Follow-up period (mo) & $43.2 \pm 18.6$ & $43.2 \pm 19.1$ & $43.5 \pm 7.6$ & 0.792 \\
\hline
\end{tabular}

Values are presented as number (\%) or mean \pm standard deviation.

PSA: prostate-specific antigen.

*Fisher exact test. 
Preoperative PSA levels in the "1st biopsy" group were $11.8 \pm 10.7 \mathrm{ng} / \mathrm{mL}$, and in the " $2 \mathrm{nd}$ or more repeated biopsies" group was $12.0 \pm 7.5 \mathrm{ng} / \mathrm{mL}$, but there was no significant difference $(\mathrm{p}=0.883)$. There were no significant differences in the D'Amico classification (low versus intermediate versus high), surgical technique (open versus laparoscopic versus robot-assisted), or presence of lymphovascular invasion (LVI) between the 2 groups ( $\mathrm{p}=0.058$, $\mathrm{p}=0.451$, and $\mathrm{p}=0.614$, respectively). However, the " 2 nd or more repeated biopsies" group exhibited more localized pathologic $\mathrm{T}$ stage cancers and this was statistically significant $(\mathrm{p}=0.003)$. Furthermore, the " 2 nd or more repeated biopsies" group exhibited lower Gleason scores and lower rates of positive surgical margins, both being statistically significant ( $\mathrm{p}=0.002$ and $\mathrm{p}=0.001$, respectively).

There were no significant differences in estimated blood loss volumes, operation times, hospital stays, and time to removal of urethral catheter between the 2 groups (all $\mathrm{p}>$
0.05). There were no significant differences in the rates of Clavien-Dindo complications between the 2 groups $(\mathrm{p}>$ 0.05). The mean follow-up period (at least more than 12 months) was $43.2 \pm 18.6$ months and overall $\mathrm{BCR}$ rate was $19.0 \%$. There were no significant differences in BCR rates between the 2 groups $(19.2 \%$ vs. $15.2 \%, p=0.414)$ according to univariate analysis.

According to multivariable Cox regression analyses, the significant risk factors for predicting BCR after radical prostatectomy were pathologic $\mathrm{T}$ stage, Gleason score, presence of LVI, and positive surgical margins (all $\mathrm{p}<0.05$ ) (Table 2). However, the Cox proportional hazards model indicated that there was no association between the number of prior prostate biopsies and BCR $(\mathrm{p}=0.210)$.

To minimize confounding, positive surgical margin (PSM) analysis was performed to compare the 1st biopsy and 2nd or more repeated biopsies groups in 66 matched pairs. Likewise, there were no significant differences in esti-

Table 2. Multivariable Cox regression analyses (MVAs) predicting biochemical recurrence in patients according to number of prior biopsies

\begin{tabular}{|c|c|c|}
\hline \multirow{2}{*}{ Variable } & \multicolumn{2}{|c|}{ MVA including use of 1 biopsy versus 2 or more biopsies } \\
\hline & HR $(95 \%$ CI $)$ & p-value \\
\hline Age & $1.02(0.99-1.04)$ & 0.159 \\
\hline Prostate-specific antigen & $1.00(0.98-1.01)$ & 0.499 \\
\hline \multicolumn{3}{|l|}{ Pathologic $\mathrm{T}$ stage } \\
\hline $\mathrm{T} 2$ & 1.00 (Reference) & \\
\hline $\mathrm{T} 3 \mathrm{a}$ & $1.70(1.19-2.42)$ & 0.004 \\
\hline$\geq \mathrm{T} 3 \mathrm{~b}$ & $1.58(1.02-2.47)$ & 0.043 \\
\hline \multicolumn{3}{|l|}{ Gleason score } \\
\hline 6 & 1.00 (Reference) & \\
\hline 7 & $2.58(1.04-6.40)$ & 0.041 \\
\hline 8 & $3.67(1.42-9.46)$ & 0.007 \\
\hline$\geq 9$ & $5.06(1.95-13.17)$ & 0.001 \\
\hline \multicolumn{3}{|l|}{ Lymphovascular invasion } \\
\hline No & 1.00 (Reference) & \\
\hline Yes & $1.48(1.05-2.10)$ & 0.026 \\
\hline \multicolumn{3}{|l|}{ Surgical margin status } \\
\hline Negative & 1.00 (Reference) & \\
\hline Positive & $1.41(1.02-1.95)$ & 0.036 \\
\hline \multicolumn{3}{|l|}{ Surgical technique } \\
\hline Robot-assisted & 1.00 (Reference) & \\
\hline Laparoscopic & $1.03(0.64-1.64)$ & 0.914 \\
\hline Open & $0.78(0.54-1.15)$ & 0.212 \\
\hline \multicolumn{3}{|l|}{ No. of prior biopsies } \\
\hline 1 & 1.00 (Reference) & \\
\hline 2 & $1.52(0.79-2.94)$ & 0.210 \\
\hline
\end{tabular}

HR: hazard ratio, CI: confidence interval. 
mated blood loss volumes, operation times, hospital stays, and time to removal of urethral catheter between the 2 groups after PSM analysis (all p>0.05) (Table 3).

Kaplan-Meier curve analysis indicated that BCR-free sur- vival rates between the 2 groups were similar $(\mathrm{p}=0.711)$ (Fig. 1).

Table 3. Perioperative characteristics and pathologic outcomes according to number of prior biopsies after propensity score matching adjustment

\begin{tabular}{|c|c|c|c|}
\hline \multirow{2}{*}{ Variable } & \multicolumn{2}{|c|}{ No. of biopsy sessions } & \multirow{2}{*}{ p-value } \\
\hline & 1 & $\geq 2$ & \\
\hline No. of patients & $264(80)$ & $66(20)$ & - \\
\hline Age (yr) & $67.7 \pm 5.8$ & $67.65 \pm 5.82$ & 0.199 \\
\hline Body mass index $\left(\mathrm{kg} / \mathrm{m}^{2}\right)$ & $24.5 \pm 2.9$ & $24.17 \pm 2.93$ & 0.474 \\
\hline Preoperative PSA $(\mathrm{ng} / \mathrm{mL})$ & $11.6 \pm 9.7$ & $12.01 \pm 7.52$ & 0.756 \\
\hline D'Amico classification & & & 0.030 \\
\hline Low & $15(5.7)$ & $10(15.2)$ & \\
\hline Intermediate & $135(51.1)$ & $34(51.5)$ & \\
\hline High & $114(43.2)$ & $22(33.3)$ & \\
\hline Pathologic $\mathrm{T}$ stage & & & $<0.001$ \\
\hline $\mathrm{T} 2$ & $125(47.3)$ & $52(78.8)$ & \\
\hline T3a & $92(34.8)$ & $9(13.6)$ & \\
\hline$\geq \mathrm{T} 3 \mathrm{~b}$ & $47(17.8)$ & $5(7.6)$ & \\
\hline Gleason score & & & 0.005 \\
\hline 6 & $26(9.8)$ & $17(25.8)$ & \\
\hline 7 & $159(60.2)$ & $36(54.5)$ & \\
\hline 8 & $34(12.9)$ & $7(10.6)$ & \\
\hline$\geq 9$ & $45(17.0)$ & $6(9.1)$ & \\
\hline Surgical technique & & & 0.462 \\
\hline Open & $34(12.9)$ & $12(18.2)$ & \\
\hline Laparoscopic & $43(16.3)$ & $12(18.2)$ & \\
\hline Robot-assisted & $187(70.8)$ & $42(63.6)$ & \\
\hline Lymphovascular invasion & & & 0.412 \\
\hline No & $229(86.7)$ & $60(90.9)$ & \\
\hline Yes & $35(13.3)$ & $6(9.1)$ & \\
\hline Surgical margin status & & & $<0.001$ \\
\hline Negative & $115(43.6)$ & $46(69.7)$ & \\
\hline Positive & $149(56.4)$ & $20(30.3)$ & \\
\hline Estimated blood loss (mL) & $273.5 \pm 160.2$ & $242.6 \pm 125.1$ & 0.145 \\
\hline Operation time (min) & $228.2 \pm 62.3$ & $221.59 \pm 47.06$ & 0.419 \\
\hline Hospital stay (day) & $9.1 \pm 2.7$ & $8.7 \pm 2.6$ & 0.432 \\
\hline Time to removal of urethral catheter (day) & $7.5 \pm 1.8$ & $7.6 \pm 1.0$ & 0.651 \\
\hline Clavien-Dindo complication & & & 0.980 \\
\hline None & $219(83.0)$ & $54(81.8)$ & \\
\hline I & $9(3.4)$ & $2(3.0)$ & \\
\hline II & $24(9.1)$ & $6(9.1)$ & \\
\hline IIIa & $8(3.0)$ & $3(4.5)$ & \\
\hline IIIb & $4(1.5)$ & $1(1.5)$ & \\
\hline$\geq \mathrm{IV}$ & $0(0)$ & $0(0)$ & \\
\hline Biochemical recurrence & & & 0.183 \\
\hline No & $203(76.9)$ & $56(84.8)$ & \\
\hline Yes & $61(23.1)$ & $10(15.2)$ & \\
\hline
\end{tabular}

Values are presented as number (\%) or mean \pm standard deviation.

PSA: prostate-specific antigen. 


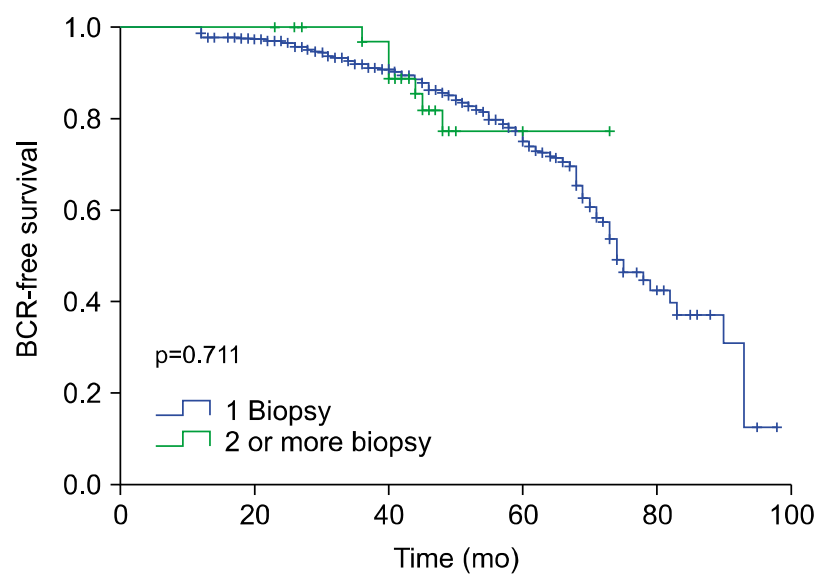

Fig. 1. Probability estimates of biochemical recurrence (BCR)-free survival in all patients stratified by number of prior biopsies using Kaplan-Meier curve.

\section{DISCUSSION}

In the United States, more than 160,000 transrectal ultrasound (TRUS) guided prostate biopsies are performed each year. ${ }^{16}$ Prostate biopsy is uncomfortable, invasive for patients, and there are many related complications, including very low percent ratio of sepsis. ${ }^{17}$ Standard procedure, TRUS guided biopsy is not lesion-targeted and cause frequent false-negative results with samples less than $1 \%$ of the prostate gland. ${ }^{18}$ Although the application of a randomized prostate biopsy as a standard method of the biopsy for PCa significantly improves the accuracy of diagnosis, but just $20-30 \%$ of $\mathrm{PCa}$ lesions are detected during an initial biopsy; the rest is clinically followed and may require repeated biopsies. ${ }^{8,19}$ It is not easily understood why an initial prostate biopsy results may be negative for prostate with cancer, but several factors such as unskillful urologist to target the prostate and the spatial distribution, multifocal and size of carcinoma foci may provide some explanation. ${ }^{20}$

To date, there are no definite guidelines about when or whether performing a second prostate biopsy in suspected patients to harbor PCa clinically, but who present negative findings upon an initial biopsy. Therefore, it is important to understand the clinical significance of PCa detected upon repeat biopsy when counseling patients who were not diagnosed with cancer upon the initial prostate biopsy.

In 2016, Elshafei et al. ${ }^{21}$ demonstrated a lower risk of pathological outcome after radical prostatectomy in men diagnosed with a favorable risk PCa when repeating a prostate biopsy than men who were diagnosed with initial prostate biopsy. They divided 422 patients who met the National Comprehensive Cancer Network's "very low-risk" ( $n=199)$ and "low-risk" (n=223) PCa definitions and who underwent radical prostatectomy. They found that compared with repeating prostate biopsies, patient diagnosed with an initial prostate biopsy displayed higher Gleason scores $(\geq 7)$ $(57.7 \%$ vs. $42.1 \%, \mathrm{p}=0.005)$ and extraprostatic extension ( $14.1 \%$ vs. $5.4 \%, p=0.01)$. However, they did not analyze whether there were any associations between biopsy session and perioperative complications.

More recently, in 2017, Rosenbaum et al. ${ }^{6}$ retrospectively analyzed the medical records about 12,624 patients who had radical prostatectomy from 2007 to 2013. According to this study, $10.8 \%$ underwent 2 nd or more repeated sessions of prostate biopsy. With a median follow-up of 36.6 months, multiple prostate biopsy groups more often presented with organ-confined tumors and more favorable perioperative complication rates $(p<0.05)$. Gleason scores and status of surgical margin were not different. They concluded that the overall $\mathrm{BCR}$ rate was $18.9 \%$ and it could be comparable among the groups. There is no association between the number of prostate biopsies and BCR.

In our study, 2nd or more repeated prostate biopsies were not related to adverse pathologic results in Korean patients and the number of biopsy sessions did not reveal any negative effects on $\mathrm{BCR}$ or perioperative complications. In 2001, Djavan et al. ${ }^{12}$ demonstrated that patients undergoing repeated biopsies more tend to have organ-confined disease during radical prostatectomy. At least $10 \%$ of patients with negative prostate biopsy were diagnosed with $\mathrm{PCa}$ during repeated biopsies. Although there were differences in location and multifocality, they concluded that the pathological and biochemical characteristics of cancers detected upon initial and repeated biopsies were similar, suggesting similar biological behaviors; thus, advocating repeated prostate biopsies in cases of negative findings upon an initial biopsy. A comparable study was also reported in 2006. LopezCorona et al. ${ }^{14}$ retrospectively reviewed 1,357 patients performed with retropubic radical prostatectomy between 1983 and 2001. PCa was diagnosed in 1,042 patients (77\%) during the first biopsy, in 227 (17\%) upon second biopsy, in 59 (4\%) upon third biopsy, and in 29 (2\%) upon fourth or later biopsy. Patients who underwent 2 nd or more repeated 
biopsies revealed a higher proportion of clinical T1c-stage cancer $(p<0.0001)$. They found that despite these more favorable pathological results, there were no differences in BCR rates. Other 2 similar studies exist that support these results. ${ }^{15,22}$ In 2012 , Kopp et al. ${ }^{15}$ retrospectively analyzed 2,739 men with $\mathrm{PCa}$ who underwent radical prostatectomy enrolled in the SEARCH database. Multiple prostate biopsies are not associated with BCR. Another study performed by Park et al. ${ }^{22}$ in 2012, patients diagnosed as PCa after repeat biopsy showed more favorable pathologic outcomes after radical prostatectomy (initial biopsy group [ $n=637]$ vs. repeat biopsy group [n=63]).

The present study has some limitations. First, it is a retrospective design. Second, the number of patients who underwent 2 nd or more repeated biopsies is too small a number $(\mathrm{n}=66)$. Heterogeneous groups of patients, no single surgeon and variable surgical techniques are also limitation. Third, this study did not evaluate whether the gap between the biopsy and the radical prostatectomy affected the perioperative results. In 2014, Park et al. ${ }^{23}$ showed that biopsy-to-surgery interval did not affect positive surgical margin status, operative time, or estimated blood loss in radical prostatectomy. Fourth, we could not gather the exact number of prostate biopsy cores from the other centers. In 2017, Carneiro et al. $^{24}$ demonstrated that a greater number of transrectal ultrasound-guided prostate biopsy cores were shown to be related to higher blood loss volumes and perioperative complications during radical prostatectomy. They included a total of 1,042 patients in group 1 ( $\leq 12$ cores) and 1,012 patients in group 2 ( $>12$ cores). The incidence of perioperative complications increased with the number of biopsies (group 1, 6.4\% vs. group 2, 8.5\%; $\mathrm{p}=0.03$ ). Multivariable logistic regression analysis indicated that group 2 presented with a 39\% higher rate of experiencing perioperative complications during robot-assisted radical prostatectomy. In our study, it was impossible to analyze whether the number of biopsy cores influenced perioperative complications. It is the same for mean prostate volume and tumor volume, for which we could not collect the pathologic reports from other centers. Therefore, large-scale, prospective studies are needed in the future.

\section{CONCLUSIONS}

Repeated prostate biopsies are not related to a rising risk of perioperative complications, adverse outcomes of pathology, or higher rates of BCR in men who have undergone radical prostatectomy.

\section{CONFLICT OF INTEREST}

The authors claim no conflicts of interest.

\section{REFERENCES}

1. Siegel RL, Miller KD, Jemal A. Cancer statistics, 2017. CA Cancer J Clin 2017;67:7-30.

2. $\mathrm{Pu}$ YS, Chiang HS, Lin CC, Huang CY, Huang KH, Chen J. Changing trends of prostate cancer in Asia. Aging Male 2004;7:120-32.

3. Jung KW, Won YJ, Oh CM, Kong HJ, Lee DH, Lee KH; Community of population-based regional cancer registries. Cancer statistics in Korea: incidence, mortality, survival, and prevalence in 2014. Cancer Res Treat 2017;49: 292-305.

4. Schröder FH. Landmarks in prostate cancer screening. BJU Int 2012;110 Suppl 1:3-7.

5. Heidenreich A, Bastian PJ, Bellmunt J, Bolla M, Joniau $\mathrm{S}$, van der Kwast $\mathrm{T}$, et al. EAU guidelines on prostate cancer. Part 1: screening, diagnosis, and local treatment with curative intent-update 2013. Eur Urol 2014;65:12437.

6. Rosenbaum CM, Mandel P, Tennstedt P, Boehm K, Chun FK, Graefen M, et al. The impact of repeat prostate biopsies on oncologic, pathological and perioperative outcomes after radical prostatectomy. J Urol 2017;197:103-8.

7. Durkan GC, Sheikh N, Johnson P, Hildreth AJ, Greene DR. Improving prostate cancer detection with an extended-core transrectal ultrasonography-guided prostate biopsy protocol. BJU Int 2002;89:33-9.

8. Fink KG, Hutarew G, Lumper W, Jungwirth A, Dietze O, Schmeller NT. Prostate cancer detection with two sets of ten-core compared with two sets of sextant biopsies. Urology 2001;58:735-9.

9. Hong YM, Lai FC, Chon CH, McNeal JE, Presti JC Jr. Impact of prior biopsy scheme on pathologic features of cancers detected on repeat biopsies. Urol Oncol 2004; 22:7-10

10. Ha JY, Shin TJ, Jung W, Kim BH, Park CH, Kim CI. Updated clinical results of active surveillance of very- 
low-risk prostate cancer in Korean men: 8 years of follow-up. Investig Clin Urol 2017;58:164-70.

11. Moussa AS, Jones JS, Yu C, Fareed K, Kattan MW. Development and validation of a nomogram for predicting a positive repeat prostate biopsy in patients with a previous negative biopsy session in the era of extended prostate sampling. BJU Int 2010;106:1309-14.

12. Djavan B, Mazal P, Zlotta A, Wammack R, Ravery V, Remzi M, et al. Pathological features of prostate cancer detected on initial and repeat prostate biopsy: results of the prospective European Prostate Cancer Detection study. Prostate 2001;47:111-7.

13. Tan N, Lane BR, Li J, Moussa AS, Soriano M, Jones JS. Prostate cancers diagnosed at repeat biopsy are smaller and less likely to be high grade. J Urol 2008;180:1325-9.

14. Lopez-Corona E, Ohori M, Wheeler TM, Reuter VE, Scardino PT, Kattan MW, et al. Prostate cancer diagnosed after repeat biopsies have a favorable pathological outcome but similar recurrence rate. J Urol 2006;175:923-7.

15. Kopp RP, Stroup SP, Schroeck FR, Freedland SJ, Millard F, Terris MK, et al. Are repeat prostate biopsies safe? A cohort analysis from the SEARCH database. J Urol 2012; 187:2056-60.

16. Loeb S, Carter HB, Berndt SI, Ricker W, Schaeffer EM. Complications after prostate biopsy: data from SEERMedicare. J Urol 2011;186:1830-4.

17. Loeb S, Vellekoop A, Ahmed HU, Catto J, Emberton M, Nam R, et al. Systematic review of complications of prostate biopsy. Eur Urol 2013;64:876-92.

18. Wolters T, van der Kwast TH, Vissers CJ, Bangma CH, Roobol M, Schröder FH, et al. False-negative prostate needle biopsies: frequency, histopathologic features, and fol- low-up. Am J Surg Pathol 2010;34:35-43.

19. Djavan B, Zlotta A, Remzi M, Ghawidel K, Basharkhah A, Schulman CC, et al. Optimal predictors of prostate cancer on repeat prostate biopsy: a prospective study of 1,051 men. J Urol 2000;163:1144-8.

20. Park DJ, Kim KH, Kwon TG, Kim CI, Park CH, Park JS, et al. Clinicopathologic differences between prostate cancers detected during initial and repeat transrectal ultrasound-guided biopsy in Korea. Korean J Urol 2014; 55:718-24.

21. ElShafei A, Nyame Y, Kara O, Badawy A, Amujiogu I, Fareed K, et al. More favorable pathological outcomes in men with low risk prostate cancer diagnosed on repeat versus initial transrectal ultrasound guided prostate biopsy. J Uro 2016;195:1767-72.

22. Park M, You D, Yoon JH, Jeong IG, Song C, Hong JH, et al. Does repeat biopsy affect the prognosis of patients with prostate cancer treated with radical prostatectomy? Analysis by the number of cores taken at initial biopsy. BJU Int 2012;109:1474-9.

23. Park B, Choo SH, Jeon HG, Jeong BC, Seo SI, Jeon SS, et al. Interval from prostate biopsy to radical prostatectomy does not affect immediate operative outcomes for open or minimally invasive approach. J Korean Med Sci 2014;29:1688-93.

24. Carneiro A, Sivaraman A, Sanchez-Salas R, Nunes-Silva I, Baghdadi M, Srougi V, et al. Higher number of transrectal ultrasound guided prostate biopsy cores is associated with higher blood loss and perioperative complications in robot assisted radical prostatectomy. Actas Urol Esp 2017;41:155-61. 